DOI 10.29184/1980-7813.rcfmc.209.vol.13.n2.2018

\title{
SÍNDROME DE VEIA CAVA SUPERIOR: RELATO DE CASO
}

\author{
SUPERIOR VENA CAVA SYNDROME: CASE REPORT
}

\begin{abstract}
Maria Fernanda Fernandes Duarte Costa ${ }^{1 *}$, Paula Morette de Oliveira ${ }^{1}$, Sandyelle da Silva Rocha ${ }^{1}$, Kassia Piraciaba Barbosa $^{1}$, Janaína Rangel Lobo ${ }^{2}$,Frederico Paes Barbosa ${ }^{3}$, Alvaro Ribeiro Gomes Neto ${ }^{4}$

1: Médica Residente de Clínica Médica do Hospital Álvaro Alvim. ${ }^{2:}$ Médica Residente de Oncologia Clínica do Hospital Álvaro Alvim. ${ }^{3:}$ Médico Professor Adjunto de Clínica Médica da Faculdade de Medicina de Campos. ${ }^{4:}$ Médico formado pela Faculdade de Medicina de Campos.
\end{abstract}

*Maria Fernanda Fernandes Duarte Costa. Rua Voluntários da Pátria, 65. Centro. Campos dos Goytacazes - RJ. CEP:

28035-260.CEL: (22) 981422686.EMAIL:mfernandafdc@yahoo.com.br

Instituição: Hospital Escola Álvaro Alvim. Rua Barão da Lagoa Dourada, 409 - Centro, Campos dos Goytacazes - RJ, $28035-211$.

\section{Resumo}

A Síndrome de Veia Cava Superior (SVCS) ocorre quando há obstrução da veia cava superior. As causas mais comuns da SVCS são as malignidades, sendo o câncer de pulmão do subtipo histológico de pequenas células a segunda principal causa. Os autores descrevem um caso de síndrome de veia cava superior por carcinoma neuroendócrino de pequenas células (tipo oat cell) em uma paciente tabagista com queixa de tosse, dispneia, edema e pletora facial. O alívio dos sintomas obstrutivos representa o tratamento inicial. A radioterapia não deve ser indicada empiricamente, já que requer o diagnóstico histológico de malignidade.

\begin{abstract}
Superior vena cava syndrome (SVCS) occurs when there is obstruction of the superior vena cava. The most common causes of SVCS are malignancies and small cell lung cancer is its second major etiology. The authors describe a case of superior vena cava syndrome caused by small cell lung cancer (oat cell type) in a smoker complaining of cough, dyspnea, facial edema and plethora. Relief of obstructive symptoms represents the initial treatment. Radiation therapy should not be indicated empirically, since it requires the histological diagnosis of malignancy.
\end{abstract}




\section{INTRODUÇÃO}

A Síndrome de Veia Cava Superior (SVCS) ocorre quando há obstrução da veia cava superior, levando à estase do retorno venoso do segmento braquiocefálico. As causas mais comuns da SVCS são as malignidades, sendo o câncer de pulmão do subtipo histológico de pequenas células a segunda principal causa.

As manifestações clínicas dependem do grau de compressão venosa, da presença de colaterais, da velocidade de instalação e da causa subjacente. Os sinais e sintomas mais comuns são edema facial e de membros superiores, dispneia, tosse, rouquidão, pletora facial e veias colaterais distendidas em pescoço e tórax. Somente deve ser considerada emergência oncológica quando estão presentes sintomas neurológicos.

O diagnóstico é clínico, podendo ser confirmado com exames de imagem. A tomografia de tórax com contraste representa o exame inicial de escolha. O diagnóstico histológico é necessário para confirmação da malignidade e para escolha do tratamento. Nos casos de malignidades, o tratamento inclui o alívio dos sintomas obstrutivos e o tratamento do câncer. A radioterapia é um tratamento padrão para alívio dos sintomas, mas requer o diagnóstico histológico. A quimioterapia é usada nos tumores sensíveis.

\section{OBJETIVO}

Descrever um caso de síndrome de veia cava superior por carcinoma neuroendócrino de pequenas células (tipo oat cell).

\section{DESCRIÇÃOO}

Mulher, 42 anos de idade, admitida no serviço de clínica médica com queixa de tosse seca, associada à dispneia aos grandes esforços e dor pleurítica à inspiração profunda, há 5 meses. Notou também edema facial e de membros superiores e surgimento de rouquidão, astenia e anorexia há 3 meses. Nega emagrecimento significativo. Tabagista (30 anos/maço) e etilista social atualmente, mas com relato de consumo excessivo de destilados e fermentados por 5 anos, sem carga etílica conhecida. Refere uso de cocaína e exposição à fumaça de metais pesados e fumaça de fogão à lenha.

Ao exame físico, apresentava-se hipocorada $(+/$ $4+)$ com pletora e edema facial $(+++/ 4+)$. Os membros superiores estavam edemaciados $(++/ 4+)$. O murmúrio vesicular era diminuído em bases, com macicez à percussão, frêmito tóraco-vocal diminuído principalmente à direita, com sibilos difusos. Sem alterações em abdome e membros inferiores.

Diante o diagnóstico clínico de SVCS, foram instituídas medidas de suporte como elevação da cabeça, uso de diurético e corticoterapia com dexametasona, para alívio dos sintomas obstrutivos. A radiografia de tórax evidenciava um volumoso derrame pleural à direita. A tomografia computadorizada do tórax mostrou formação expansiva com densidade de partes moles e realce pelo contraste, de limites mal definidos e aspecto infiltrativo, na região peri-hilar direita, estendendo-se longitudenalmente do plano da veia braquiocefálica até o plano do átrio esquerdo, compatível com lesão neoplásica. (Figura 1)

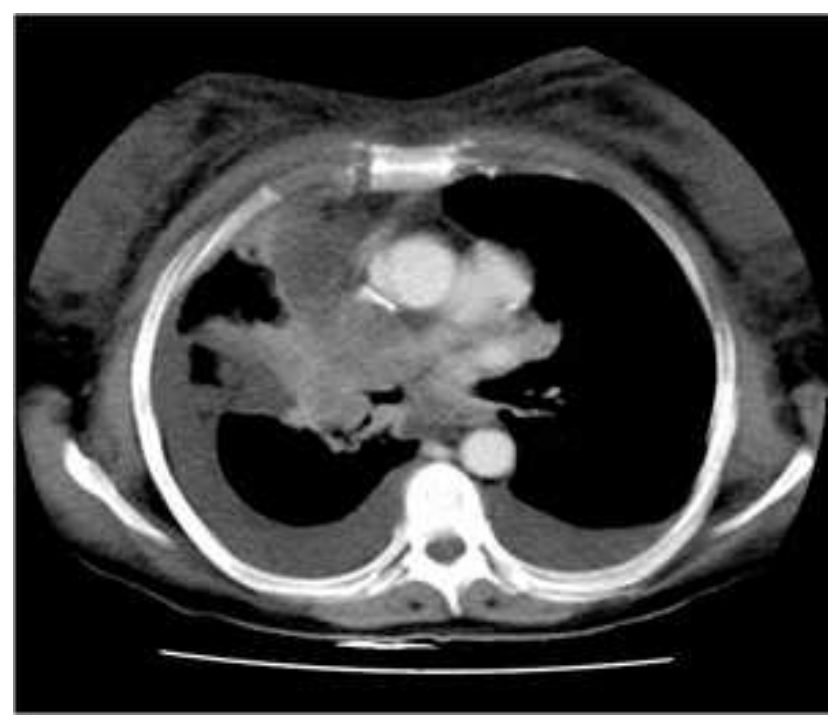

Figura 1

Esta lesão também envolve completamente a veia cava superior e a artéria pulmonar direita, determinando importante redução da luz destes vasos, além de derrame pleural bilateral, maior à direita. Então, a paciente foi submetida à drenagem de tórax em selo d'água para alívio do derrame pleural e, posteriormente, à broncofibroscopia que revelou lesão séssil em carina secundária com brônquio de lobo superior e brônquio intermediário, sendo realizada biópsia com retirada de 4 fragmentos. O dreno de tórax retirado após 4 dias.

Os achados histológicos revelaram fragmentos de mucosa respiratória exibindo córion em proliferação atípica de pequenas células de padrão difuso, sendo necessária complementação do estudo com imunohistoquímica para pesquisa de linhagem de diferenciação celular e classificação definitiva. $\mathrm{O}$ 
estudo imuno-histoquímico concluiu o diagnóstico de carcinoma neuroendócrino de pequenas células (tipo oat cell).

Foi iniciado esquema CAV (Ciclofosfamida, Doxorubicina e Vincristina). Após 2 meses, a paciente evoluiu com piora da dispneia, sendo indicada dose única paliativa de radioterapia e troca do esquema quimioterápico para carboplatina e etoposídeo. Atualmente, segue acompanhamento oncológico ambulatorial.

\section{CONCLUSÃO}

A SVCS tem como principal causa o câncer de pulmão, do subtipo histológico de pequenas células. Somente considerada uma verdadeira emergência oncológica quando estão presentes sintomas neurológicos. O alívio dos sintomas obstrutivos representa o tratamento inicial. A radioterapia não deve ser indicada empiricamente, já que requer o diagnóstico histológico de malignidade. Esquemas quimioterápicos podem ser utilizados em tumores sensíveis.

\section{REFERÊNCIAS}

Cohen R, Mena D, Carbajal-Mendoza R, Matos N, Karki N. Superior vena cava syndrome: A medical emergency? Int J Angiol 2008;17(1):43-46.

Condutas do INCA Carcinoma de pequenas células de pulmão. Revista Brasileira de Cancerologia, 2003, 49(3): 149-152.

Cordeiro, AZDB, Cordeiro, PDB. Síndrome de veia cava superior. J Pneumol, 2002; Set-Out 28(5): 288-293. Rice TW, Rodriguez RM, Light RW. The superior vena cava syndrome: Clinical characteristics and evolving etiology. Medicine 2006; Jan 85:37-42.

Urban T, Lebean B, Chastang C. Superior vena cava syndrome in small cell lung cancer. Arch Intern Med 1993;153:384.

Wilson LD, Detterbeck FC, Yahalom J. Superior vena cava syndrome with malignant causes. N Engl J Med 2007; Mai 356:1862-1869. 